\title{
Prey Detection and Feeding Success of the Comb Jellyfish Mnemiopsis leidyi on Copepods in Still and Turbulent Waters

\author{
Clare Elizabeth Chisholm*, Environmental Science
}

\begin{abstract}
The comb jelly or ctenophore, Mnemiopsis leidyi, is a voracious predator in both its native and non-native habitats. Though $M$. leidyi inhabits coastal waters that are frequently turbulent, previous feeding studies have been conducted in still water tanks. This study aimed to research feeding behaviors in turbulent waters, which is more representative of the natural environment. Interactions between the freeswimming ctenophores and copepod prey, such as Acartia tonsa, were observed and recorded in a laboratory turbulence tank $(n=73)$. Turbulence was created using submersible speakers, and the interactions were recorded using a video camera. Capture efficiency denoted interactions containing direct contact between copepods and $M$. leidyi that led to eventual capture, frequently after multiple contacts. Overall copepod capture efficiency was similar in still (48\%) and turbulent (43\%) water, as were the overall prey retention rates for each (still $=58 \%$; turbulent $=57 \%$ ). However, $M$. leidyi exhibited anticipatory responses, defined as altering the position of feeding structures, nearly twice as often in still $(41 \%)$ waters than in turbulent $(20 \%)$ waters. The hydromechanical "noise" produced by background turbulence may inhibit the capacity of the ctenophore to detect and respond to fluid motions produced by its prey.
\end{abstract}

\section{INTRODUCTION}

The lobate ctenophore Mnemiopsis leidyi is a planktonic predator native to the Atlantic coastal waters of North and South America, ranging from Buzzards Bay, USA $\left(40^{\circ} \mathrm{N}\right)$ to Bianca Bay, Argentina (46º $)$ (Fig. 1; Colin et al., 2010; Mianzan et al., 2010; Costello et al., 2012). Ecologically important to its native range, $M$. leidy $i$ has also become ecologically important in its invasive range, mainly due to its rapid population growth rates and high feeding rates on zooplankton and ichthyoplankton (Costello et al., 1999; Colin et al., 2010; Costello et al., 2012). In the last 30 years, $M$. leidyi has transitioned from its native waters to the Black Sea, Caspian 
Sea, Mediterranean Sea, North Sea, Baltic Sea, Sea of Azov, Sea of Marmara and the Adriatic Sea (Bright, 1999; Mutlu 1999; Finenko et al., 2006; Roohi et al., 2008; Colin et al., 2010; Costello et al., 2012). Introduced to these areas in the 1980s, it is likely that $M$. leidyi first invaded the Black Sea via ballast water and spread to the surrounding ecosystems (Mutlu 1999; Finenko et al., 2006; Roohi et al., 2008; Ghabooli et al., 2010, Costello et al., 2012). Due to the ctenophores self-compatible hermaphroditism, its tolerance to a range of temperatures, salinity and oxygen levels and its extensive dietary plasticity, $M$. leidyi has established itself as a prolific invader (Roohi et al., 2008; Ghabooli et al., 2010; Mianzan et al., 2010). Additionally, the invasion and explosion of $M$. leidyi in the European seas has been identified as a possible cause to of the collapse of fisheries in Eurasia, including that of economically important fish species, such as anchovies (Bilio and Niermann, 2004; Daskalov \& Mamedov, 2007; Costello et al., 2012).

When observed feeding in still water environments, $M$. leidyi engages the ciliary lining in the auricles, creating a laminar feeding current (Fig. 2; Colin et al., 2010). This current causes large quantities of fluid to be swept between the oral lobes, allowing the ctenophore to entrain and retain prey very efficiently (Colin et al., 2010). This capacity to process large volumes of water has greatly contributed to the ecological success of the species, and is likely one of the primary influences on the devastation of planktonic communities (Mutlu, 1999; Finenko et al., 2006; Colin et al., 2010).

Information gathered in relation to the feeding habits of $M$. leidyi has been primarily conducted in still water settings; however, water movement frequently characterizes the natural ecological habitats of $M$. leidyi. Previous research has discovered that $M$. leidyi has a $74 \%$ success capture rate after contact occurs between predator and prey. However, capture success numbers fall substantially when initial contact between species occurs on the interior surface of the oral lobes (Costello et al., 1999). This is likely because physical contact with the oral lobe of the ctenophore elicits an escape response from the copepod. Considering the importance of fluid manipulation during feeding, background water motion is a likely influence on the predation behaviors of $M$. leidyi

Turbulence is defined as the time-varying movement of water, which can be produced by wind, waves, tides, coastal upwelling and the interaction with rough surface; then disperses heat, particles and organisms throughout the ocean (Robinson et al., 2007; Thorpe, 2007). Turbulence, being the natural state of the oceanic environment, often evokes variant responses in marine organisms such as copepods and ctenophores (Warnaars et al., 2006; Thorpe, 2007). Planktonic organisms have evolved in the presence of fluid motion and are able to detect and respond to turbulence and related fluid-mechanical cues (Warnaars et al., 2006; Thorpe, 2007). For the purpose of this research, turbulence was studied in relation to the interactions between $M$. leidyi and copepods. Copepods employ sensory hairs on their antennae called setae in order to detect changes in ambient turbulence (Kiorboe, 2008). Evidence exists that copepods are capable of distinguishing the differences between environmental fluid motion cues and the cues from other plankters; ambient turbulence does not necessarily elicit the bending of the setae of a copepod, which dictate whether an attack or escape response is appropriate (Kiorboe, 2008). In 
contrast, the disturbance of water movement by predators, such as $M$. leidyi, may induce these responses from copepod individuals (Kiorboe, 2008).

The goal of this study was to compare the predator-prey encounters and feeding success rates of the adult $M$. leidyi on copepods in still and turbulent conditions. In both treatments, encounters between copepods and $M$. leidyi individuals were quantified to document the relationship between feeding success in turbulent vs. non-turbulent water. In particular, the following hypothesis was tested:

$\mathrm{H}_{\mathrm{o}}$ : Increased turbulence has no effect on the success of the predator-prey interaction between Mnemiopsis leidyi and zooplankton species in terms of retention and capture efficiencies

$\mathrm{H}_{1}$ : An increase in turbulence causes an increase in the retention and capture efficiencies of Mnemiopsis leidyi when feeding on zooplankton species

It was expected that retention and capture efficiencies would increase with increased turbulence due to the amplified noise within ambient waters. Theoretically, this would allow for $M$. leidyi individuals to ambush prey more effectively, and retain prey more efficiently (Costello et al., 1999).

\section{MATERIALS AND METHODS}

\subsection{COLLECTION}

Specimens of the ctenophore Mnemiopsis leidyi and zooplankton prey were collected in August of 2011 at the Marine Biological Labs (MBL) in Woods Hole, Massachusetts. Ctenophore specimens between 2 and $4 \mathrm{~cm}$ were dipped from the surface water using beakers. Individuals were held in tanks of ambient seawater and observed within 24 hours of collection. Additionally, zooplankton were collected, primarily Acartia tonsa, using a 0.5 meter plankton net with 333 micrometer mesh.

\subsection{TURBULENCE}

Ctenophore-copepod interactions were observed at three flow levels: still water, intermediate turbulence (24 and 27 clicks) and high turbulence (30 clicks). Turbulence was generated following the methods of Warnaars et al (2006). A rectangular tank with a removable lid was designed out of Plexiglass (dimensions $=26 \times 50 \times 30 \mathrm{~cm}$ ), with plastic mesh grids with 1-2 cm openings placed at opposite ends. Submersible speakers (Clark Synthesis AQ339) were connected to an amplifier and mounted behind the mesh grids at each end of the tank. Turbulence was produced using low frequency $\left(30 \mathrm{~Hz}\right.$ ), out-of-phase $\left(180^{\circ}\right)$ sine waves that were generated using a computer program called "Test Tone Generator." The alternation of the sine waves allowed the water to be pushed back and forth, which simulated energy dissipation levels in the natural environment. 
Each speaker was then turned to a specific volume, o clicks for still water, 24 and 27 clicks for intermediate turbulence, and 30 clicks for high turbulence. Clicks simply denoted the volume level of the speaker. The overall turbulence dissipation rate of the pooled data is as follows: mean $\pm \mathrm{SD}=3.75 \times 10^{-7} \pm 2.99 \times 10^{-7} \mathrm{~m}^{2} \mathrm{~s}^{-3}$. This number can be compared to rates of turbulence dissipation measured at the ocean surface and in estuaries. Usually, the surface rates are less than $1 \times 10^{-6} \mathrm{~m}^{2} \mathrm{~s}^{-3}$, and estuaries can reach $1 \times 10^{-3} \mathrm{~m}^{2} \mathrm{~s}^{-3}$, though they rarely encounter these sorts of levels (Noh and Hyoung, 1999).

\subsection{VIDEOGRAPHY}

For each trial, 5-8 individual $M$. leidyi were introduced to the turbulence generator and allowed to acclimate for a minimum of 10 minutes. Interactions between $M$. leidyi and copepod prey were then filmed using a Sony HDR-HC9 handheld video camcorder, stabilized on a tripod. The tank was lit using LED lights, and the movement of individual specimens was tracked with the camera. Scale bars were included within the recording periodically, in order to provide spatial context for the interactions. The total film time was approximately 3 hours and 44 minutes.

\subsection{VIDEO ANALYSIS}

Video analysis was conducted using the film-editing software iMovie 2009 (Apple Inc., version 8.0.6). Videos were observed carefully to identify interactions between $M$. leidyi and copepod individuals. Video segments encompassing encounters between $M$. leidyi and copepods spanning five seconds or greater were selected for data collection. During the five-second clips, a minimum of $75 \%$ of the ctenophore body was required to be within the entire frame as well as the interacting copepod individual. Additionally, the segments could not have more than one $M$. leidyi specimen within the frame. Video clips involving an interaction were subsequently analyzed and components of the predation process were coded following the methods of previous studies regarding $M$. leidyi predation behaviors (Costello et al., 1999); encounters were analyzed based on the following predation sequence:

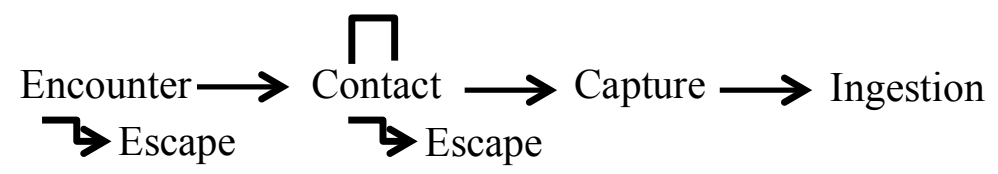

Each component is described in Table 1. Similar to research conducted by Costello et al. (1999), the two variables evaluated were retention and capture efficiency, which were defined in as the following:

\begin{tabular}{lll} 
Retention Efficiency & no. of & no. of \\
\cline { 2 - 2 } Capture Efficiency & no. of & no. of
\end{tabular}


The two efficiencies quantify two key elements of the encounters. Retention efficiency evaluates the ability of the ctenophore to retain prey post-contact. Comparatively, capture efficiency quantifies the final post-encounter outcome of $M$. leidyi and zooplankton individuals, disregarding intermediate interactions between the two species. Retention and capture efficiencies were calculated using the aforementioned equations and then statistically analyzed for significance using a chi-square test (Microsoft Excel for Mac 2011, Version 14.3.2).

\section{RESULTS}

\subsection{RETENTION AND CAPTURE EFFICIENCY}

A total of 73 encounters were observed between Mnemiopsis leidyi and copepods during the study. Of these encounters 29 occurred in still water and 44 occurred in turbulent water. Retention efficiency for still and turbulent waters was similar (Fig. 3). In still water, the retention rate was $58.3 \%$, and turbulent water interactions exhibited a retention rate of $57.6 \%$.

Capture efficiencies between treatments varied more than retention efficiencies, though there was no significant difference. Interactions occurring in still water had a capture rate of $48.3 \%$, while turbulent treatments resulted in a capture rate of $43.2 \%\left(\mathrm{X}^{2}=0.124, \mathrm{df}=1, \mathrm{p}=\right.$ $0.724)$.

\subsection{VARIATIONS IN ENCOUNTER ORIGINS}

In both treatments, encounters originated through two processes: laminar flow generated by $M$. leidyi $(\mathrm{n}=53)$ and movement of copepod individuals towards $M$. leidyi prior to interspecies contact ( $\mathrm{n}=20$; Fig. 4 ). The majority of encounters in this study originated through laminar flow created by $M$. leidyi individuals, with little variation between still and turbulent treatments ( still $=69.0 \%$; turbulent $=70.5 \%$ ). Less than half of the encounters began with pre-contact motion by the copepod prey, again with little difference between the two treatments (still = 31.0\%; turbulent $=29.6 \%$ ). No significant difference existed between still and turbulent encounter origins $\left(\mathrm{X}^{2}=0.052, \mathrm{df}=1, \mathrm{p}=0.820\right)$.

\subsection{ENCOUNTERS AND CONTACT RELATIONSHIP}

The majority of interactions between the ctenophore $M$. leidyi and copepods involved multiple contacts. Overall, encounters with multiple contacts $(n=45)$ occurred more than twice as often as interactions containing single contacts $(n=23$; Fig. 5). Additionally, interactions in turbulent waters containing multiple contacts (42.6\%) occurred nearly twice as often as encounters with multiple contacts in still waters (23.5\%). Despite these differences in frequency, there was no significant difference in contact frequency between still and turbulent treatments $\left(\mathrm{X}^{2}=0.124, \mathrm{df}=1, \mathrm{p}=0.724\right)$.

Encounters with and without anticipation were evaluated based on the number of contacts within each interaction. When anticipation was not present (Fig. 6), encounters in turbulent 
waters occurred more often, both with single (28.6\%) and multiple contacts (33.3\%). The proportion of encounters with single contacts in still water was $11.9 \%$, less than half that of turbulent encounters. Additionally, in still water encounters without anticipation, multiple contacts (26.2\%) occurred more than twice as frequently as single contacts. However, when the treatments were compared, no significant difference between proportion of encounters and contact number was seen in still vs. turbulent waters $\left(\mathrm{X}^{2}=2.249, \mathrm{df}=1, \mathrm{p}=0.134\right)$.

In contrast, anticipation occurred more often in still waters, including encounters containing single (26.7\%) and multiple (33.3\%) contacts (Fig. 7). While an increase from single contact to multiple contacts with anticipatory behaviors was seen, no significant difference was exhibited $\left(\mathrm{X}^{2}=1.238, \mathrm{df}=1, \mathrm{p}=0.266\right)$. In addition, interactions with anticipatory movement and multiple contacts (26.8\%) occurred more often than single contacts (13.3\%) in turbulent waters.

\subsection{PREY DETECTION AND PREDATION SUCCESS}

The ctenophore $M$. leidyi frequently employs anticipatory behaviors upon the detection of nearby prey. In still waters, anticipatory movements were displayed by the ctenophore $41.4 \%$ of the time (Fig. 8). In contrast, in turbulent waters anticipatory behaviors were exhibited in only 20.5\% of the interspecies encounters. However, when no anticipatory movement was present the proportion of encounters between $M$. leidyi and copepods displayed a large increase (79.6\%). A higher proportion of encounters occurred in still water without anticipatory movement (58.6\%) than with anticipatory movement. There was a significant difference between interactions with anticipatory behavior and those without anticipatory behavior in still and turbulent water $\left(\mathrm{X}^{2}=10.256, \mathrm{df}=1, \mathrm{p}=0.001\right)$.

The capture efficiency of encounters with and without anticipatory movements in still and turbulent waters displayed opposing trends (Fig. 9). For still water interactions the capture efficiency of $M$. leidyi was higher when an anticipatory motion was present (27.6\%), and lower without anticipatory behavior (20.7\%). In contrast, $M$. leidyi experienced greater capture efficiency success when no anticipatory behavior was present in turbulent waters (31.8\%), and a much lower rate of capture efficiency when anticipatory behaviors were present (11.4\%). Additionally, when capture efficiency and presence of anticipatory behavior was compared between still and turbulent treatments a significant difference was observed $\left(X^{2}=9 \cdot 342, \mathrm{df}=1\right.$, $\mathrm{p}=0.002)$.

\section{DISCUSSION}

\subsection{RETENTION AND CAPTURE EFFICIENCY}

As previously discussed, encounters between Mnemiopsis leidyi and copepods were analyzed in both turbulent and still water. It was expected that retention and capture efficiencies would be lower in still waters than in turbulent waters. However, similarities in retention and capture efficiencies between treatments were observed, suggesting that $M$. leidyi appears to be an equally effective predator on copepods in both still and turbulent waters. 
While this relationship was unexpected, it led to additional questions and observations regarding ctenophore feeding behaviors. It is possible that $M$. leidyi employed different predatory tactics within the two treatments, allowing individuals to detect and consume prey efficiently in both still and turbulent environments. These varying behaviors could include anticipatory movements, altered body positioning and selective feeding based on copepod life stage (Costello et al., 1999; Waggett and Costello, 1999). Previous studies have indicated that $M$. leidyi preferentially select late-stage and larger copepods over early-stage and smaller copepods when employing anticipatory behaviors (Costello et al., 1999; Waggett and Costello, 1999).

\subsection{ENCOUNTER ORIGINS AND FREQUENCY OF M. LEIDYI ANTICIPATION}

The origin of encounters between $M$. leidyi and copepods varied little between still water and turbulent water treatments. In both treatments, laminar flow was most often employed by the ctenophore, in order to entrain copepods. In contrast, prey motion much less frequently served as the point of origin for ctenophore-copepod interactions. These results did not correlate with previous research, as earlier studies displayed that the majority of encounters began with prey motion (Costello et al., 1999). However, these studies observed interactions between the adult-stage copepod Acartia tonsa and late-stage $M$. leidyi individuals (Costello et al., 1999; Waggett and Costello, 1999). The study performed by Costello et al. (1999) found that more frequently swimming by adult $A$. tonsa led to the interspecies encounters, but interactions between the smaller copepods Oithona colcarva were usually initiated by the laminar flow produced by $M$. leidyi

It is possible that the variation between results of this study and the results of the previous studies is due to the disparity in copepod life-history stage and species. While the majority of copepods in this study were identified as $A$. tonsa it is likely that several of these were $A$. tonsa nauplii individuals, which are substantially smaller than their adult counterparts. Additionally, it has been observed that $A$. tonsa nauplii cause a reduced disturbance in surrounding fluid when compared to adult-stage $A$. tonsa, causing the ctenophore to employ entrainment through flow when feeding on smaller individuals (Costello et al. 1999; Waggett and Costello, 1999). These factors led to the conclusion that the high frequency of encounters observed in this study originating with laminar flow are likely due to the increased presence of the smaller $A$. tonsa nauplii.

In addition to employing laminar flow more frequently, $M$. leidyi individuals in this study also seldom exhibited anticipatory movements in either still or turbulent treatments. Again, these data contradict the findings of previous studies, which found that anticipatory behavior was often exhibited in still waters (Costello et al., 1999). Similarly, these differing results regarding anticipatory behavior may be linked to the size of the copepods present (Costello et al., 1999; Waggett and Costello, 1999). In their study, Costello et al., (1999) observed that $A$. tonsa nauplii rarely elicited an anticipatory response from $M$. leidyi, likely due to their decreased disturbance to the background water motion. These slow-moving, small prey are far more likely to be entrained by the laminar flow generated by M. leidyi (Waggett and Costello, 1999). 


\subsection{INTERSPECIES CONTACT AND ANTICIPATION}

The majority of encounters in this study involved multiple contacts between species, regardless of still or turbulent treatments. However, a larger proportion of encounters in turbulent water demonstrated multiple contacts when compared to still treatments. Additionally, encounters containing multiple contacts in turbulent waters also occurred more frequently than encounters exhibiting single contacts in turbulent waters. This is possibly due to a lack of prey detection in turbulent waters, and the multiple contacts followed before $M$. leidyi could effectively capture the prey. Additionally, similar to the results of Costello et al. (1999) the bulk of escapes by copepods in this study occurred when a single contact was present, regardless of still or turbulent conditions.

In addition to the proportion of encounters with single and multiple contacts, the relationship between contact number and presence of anticipatory behaviors was analyzed. Similar to previous studies, an increase in encounters with multiple contacts and anticipation were observed in both still and turbulent waters (Costello et al., 1999). However, contradicting trends were seen in encounters exhibiting no anticipation. Earlier research found that interactions without anticipation exhibited a single contact the majority of the time, and infrequently had multiple contacts (Costello et al., 1999). While encounters in turbulent waters may display these opposing results due to the difference in background water motion, it is likely that encounters in still water differ based on prey species and size once again (Costello et al., 1999; Waggett and Costello, 1999).

As $M$. leidyi continues to expand its native and non-native range, knowledge surrounding its feeding behaviors is increasingly important. This research provides further information regarding the predation tactics and interactions of $M$. leidyi with copepods, such as $A$. tonsa, in a system replicate of its natural environment. It is possible that $M$. leidyi has shown itself to be such an effective invasive species because it successfully feeds on small prey, though it selectively anticipates larger prey (Costello et al., 1999; Waggett and Costello, 1999).

Continued examination of the feeding behaviors of $M$. leidyi in relation to varying environmental factors, such as salinity, temperature and life stage of prey and predator, would be beneficial in the understanding of the species' invasive tendencies. Additionally, research on other lobate ctenophore species may also provide insight into their influence on zooplankton communities. It remains clear that ctenophores, and $M$. leidyi specifically, play an important ecological role in the global food webs. Their consumption of species existing on some of the lowest trophic levels allows $M$. leidyi to substantially impact both native and non-native ecosystems.

\section{ACKNOWLEDGEMENTS}

I would like to thank my advisor Dr. Kelly Sutherland for providing data and guiding me throughout the entirety of my thesis. Dr. Sutherland's support was invaluable, and I would have been unable to complete this thesis without her. I would also like to thank my academic advisor 
Peg Boulay and the Environmental Science department at the University of Oregon for the extensive opportunities and support throughout my undergraduate education. Dr. Sutherland was provided funding for sample collection by a grant from the National Science Foundation. All research was collected at the Woods Hole Marine Biological Labs and analyzed at the University of Oregon.

\section{REFERENCES}

Bilio, M., and U. Niermann. "Is the comb jelly really to blame for it all? "Mnemiopsis leidyi and the ecological concerns about the Caspian Sea." Marine Ecology Progress Series. 269. (2004): 173-183.

Colin, S. P., J.H. Costello, L.J. Hansson, J. Titelman, and J.O. Dabiri. "Stealth predation and the predatory success of the invasive ctenophore Mnemiopsis leidyi." Proceedings of the National Academy of Sciences. 107.40 (2010): 17223-17227.

Costello, J.H., K.M. Bayha, H.W. Mianzan, T.A. Shiganova, and J.E. Purcell. "Transitions of Mnemiopsis leidyi (Ctenophora: Lobata) from a native to an exotic species: a review." Hydrobiologia. 690. (2012): 21-46.

Costello, J.H., R. Loftus, and R. Waggett. "Influence of prey detection on capture success for the ctenophore Mnemiopsis leidyi feeding upon adult Acartia tonsa and Oithona colcarva copepods." Marine Ecology Progress Series. 191. (1999): 207-216.

Daskalov, G.M., and E.V. Mamedov. "Integrated fisheries assessment and possible causes for the collapse of anchovy kilka in the Caspian Sea." Journal of Marine Sciences. 64. (2007): 503511.

Finenko, G.A., A.E. Kideys, B.E. Anninsky, T.A. Shiganova, A. Roohi, M.R. Tabari, H. Rostami, and S. Bagheri. "Invasive ctenophore Mnemiopsis leidyi in the Caspian Sea: feeding, respiration, reproduction and predatory impact on the zooplankton community." Marine Ecology Progress Series. 314. (2006): 171-185..

Kiorboe, T. A Mechanistic Approach to Plankton Ecology. 1st ed. 1. Princeton: Princeton University Press, 2008. 83-98. Print.

Mianzan, H.W., P. Martos, J.H. Costello, and R.A. Guerrero. "Avoidance of hydro-dynamically mixed environments by Mnemiopsis leidyi (Ctenophora: Lobata) in open-sea populations from Patagonia, Argentina." Hydrobiologia. 645. (2010): 113-123.

Mutlu, E. "Distribution and abundance of ctenophores and their zooplankton food in the Black Sea. II. Mnemiopsis leidyi." Marine Biology. 135. (1999): 603-613.

Robinson, H.E., C.M. Finelli, reef on their ability to detect and evade predators." Marine Ecology Progress Series. 349. (2007): 171-181. 
Roohi, A., Z. Yasin, A.E. Kideys, A.T. Shau Hwai, A.G. Khanari, and E. Eker-Develi. "Impact of a new invasive ctenophore (Mnemiopsis leidyi) on the zooplankton community of the Southern Caspian sea." Marine Ecology. 29. (2008): 421-434.

Shiganova T.A. "Ctenophore Mnemiopsis leidyi (A.Agassiz) in the Azov and Black Sea and consequences of its intrusion." Rostov-on-Don. (2000): 33-75.

Thorpe, S.A. An Introduction to Ocean Turbulence. 1st ed. 1. Cambridge: Cambridge University Press, 2007. 1-152. Print.

Waggett, R., and J.H. Costello. "Capture mechanisms used by the lobatectenophore, Mnemiopsis leidyi, preying on the copepod Acartia tonsa." Journal of Plankton Research. 21.11 (1999): 2037-2052.

Warnaars, T.A., M. Hondzo, and M.A. Carper. "A desktop apparatus for studying interactions between microorganisms and small-scale fluid motion." Hydrobiologia. 563. (2006): 431443.443 . 


\section{TABLES AND FIGURES}

\begin{tabular}{|c|c|}
\hline Variable & Description \\
\hline Encounter & $\begin{array}{l}\text { Interaction between ctenophore and copepod within the encounter zone, } \\
\text { initiated either by direct contact between ctenophore and copepod or by an } \\
\text { anticipatory response (e.g. oral lobe folding) by ctenophore prior to } \\
\text { contact with copepod. The encounter zone was defined as the area } \\
\text { bounded on the sides by the interior lobes of the ctenophore and extending } \\
\text { anterior to the lobes for } 3 \mathrm{~mm} \text { (approximately } 2 \text { Acartia tonsa body } \\
\text { lengths). Encounters terminated in either an escape from the encounter } \\
\text { region or capture of the copepod by the ctenophore }\end{array}$ \\
\hline Encounter origin & $\begin{array}{l}\text { Means of encounter initiation; either flow entrainment or self-propelled } \\
\text { swimming by the copepod. Copepod motion relative to surrounding flow } \\
\text { was readily confirmed by visually comparing copepod velocities with } \\
\text { those of surrounding particles entrained within flow field }\end{array}$ \\
\hline Contact & $\begin{array}{l}\text { Physical collision of predator and prey bodies. An encounter could entail } \\
\text { multiple contacts if the copepod was not retained and collided with } \\
\text { another portion of the ctenophore's capture surfaces. Contacts with } \\
\text { exterior portions of the ctenophore's body (e.g. lobe exterior) were not } \\
\text { recorded as contacts because these could not result in capture and were } \\
\text { outside the encounter zone }\end{array}$ \\
\hline Escape & $\begin{array}{l}\text { Evasion of capture by a copepod after encounter with a ctenophore; the } \\
\text { copepod must have left the encounter zone. Contact was not required }\end{array}$ \\
\hline Capture & Copepod subdued and consumed by ctenophore \\
\hline Anticipatory response & $\begin{array}{l}\text { Lobe or auricle motion of ctenophore in response to copepod prior to } \\
\text { actual contact }\end{array}$ \\
\hline Prey motion & Motion of copepod prey in the vicinity of the ctenophore prior to contact \\
\hline Number of contacts & $\begin{array}{l}\text { Number of contacts between the ctenophore and copepod during an } \\
\text { encounter }\end{array}$ \\
\hline Encounter outcome & Capture or escape of a copepod as a result of an encounter \\
\hline
\end{tabular}

Table 1 Patterns of copepod-ctenophore encounters (Costello et al., 1999). 


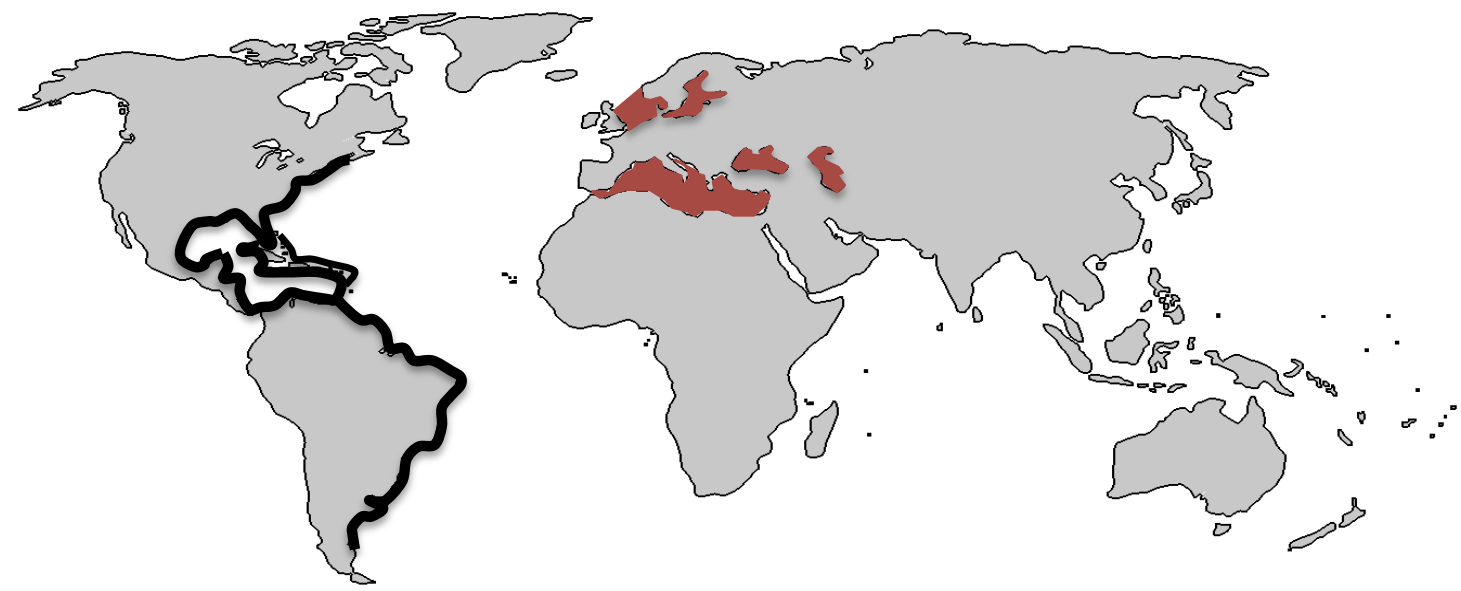

Figure 1 Map of the native and invasive ranges of Mnemiopsis leidyi. The black line represents the native range of the species and the red represents the invasive territory.

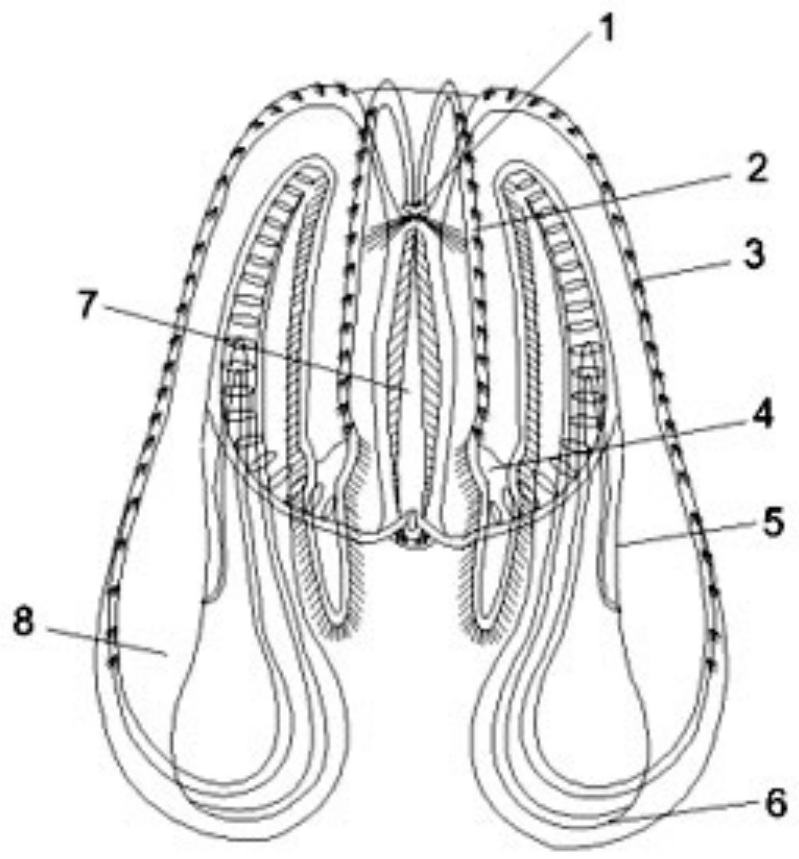

Figure 2 Mnemiopsis leidyi. (1) aboral organ, (2) subtentacular row of comb flappers, (3) subsagital row of comb flappers, (4) auriculus, (5) subsagital tube, (6) translobal tube, (7) tentacular tube, (8) lobe (Shiganova, 2000).As compared to 2011, the 2012 sediment size distribution in Middle McKenzie side channel 4 shifted toward a smaller median pebble size with an increase in $\mathrm{D}_{84}$ in count 1 , while median pebble size increased with no detectable change in $\mathrm{D}_{84}$ values for count 2 (Figure 2). For count 1, the $\mathrm{D}_{50}$ size class decreased from $45-64$ $\mathrm{mm}$ to a size class of $32-45 \mathrm{~mm}$ and the $\mathrm{D}_{84}$ size class increased from $91-128 \mathrm{~mm}$ to $128-181 \mathrm{~mm}$. For count 2 , the $\mathrm{D}_{50}$ size class increased from $32-45 \mathrm{~mm}$ to $45-64 \mathrm{~mm}$ and the $\mathrm{D}_{84}$ size class was recorded at $91-128 \mathrm{~mm}$ both years. 


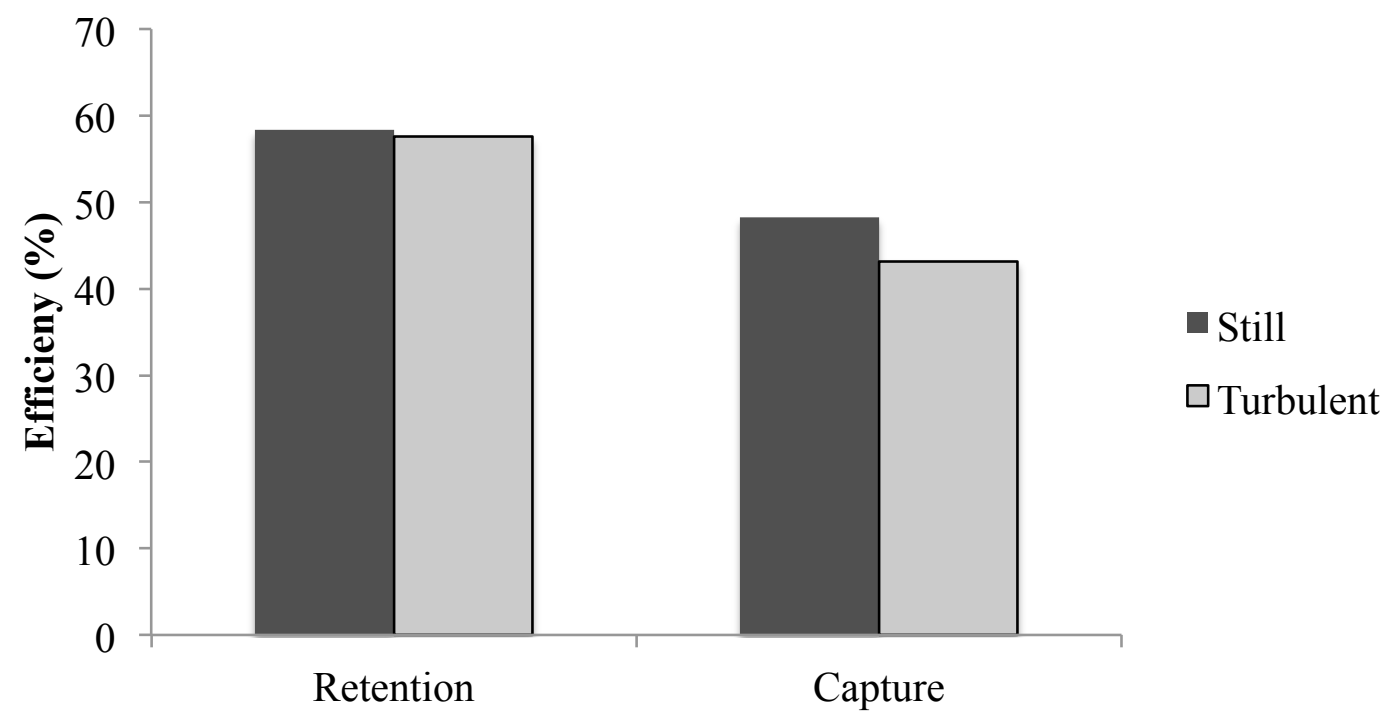

Figure 3 Retention and capture efficiencies of encounters between Mnemiopsis leidyi and copepods that occurred in still $(\mathrm{n}=29)$ and turbulent $(\mathrm{n}=44)$ waters.

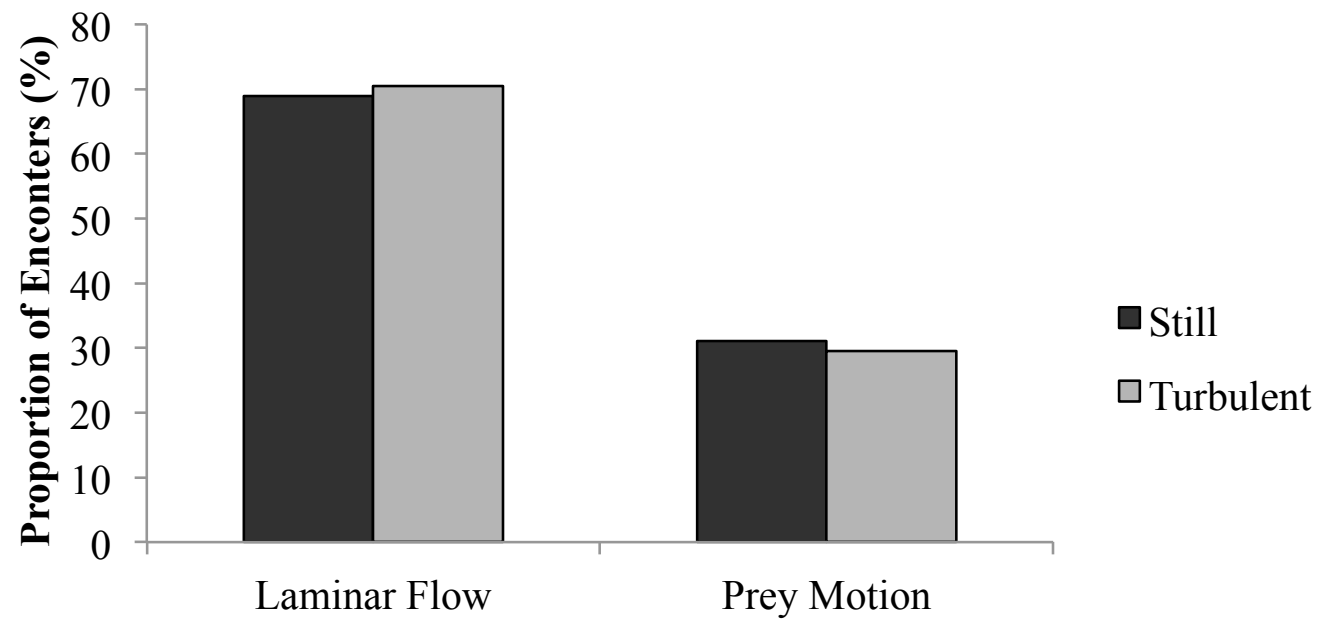

Encounter Origin

Figure 4 Origin of encounters between Mnemiopsis leidyi and copepods in still and turbulent water treatments. Encounters began with either entrainment by $M$. leidyi (laminar flow) or independent movement by copepods (prey motion). 


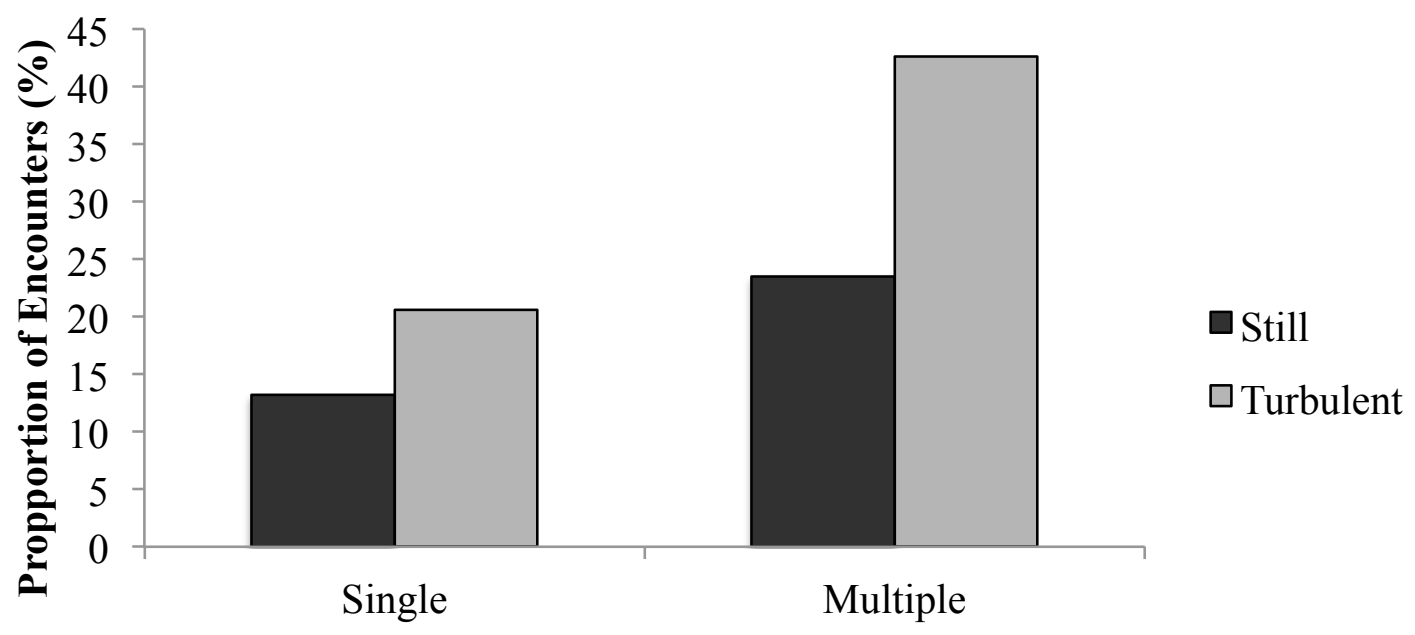

Number of Contacts

Figure 5 Frequency of encounters containing single and multiple contacts between Mnemiopsis leidyi and copepods in still $(n=25)$ and turbulent $(n=43)$ waters.

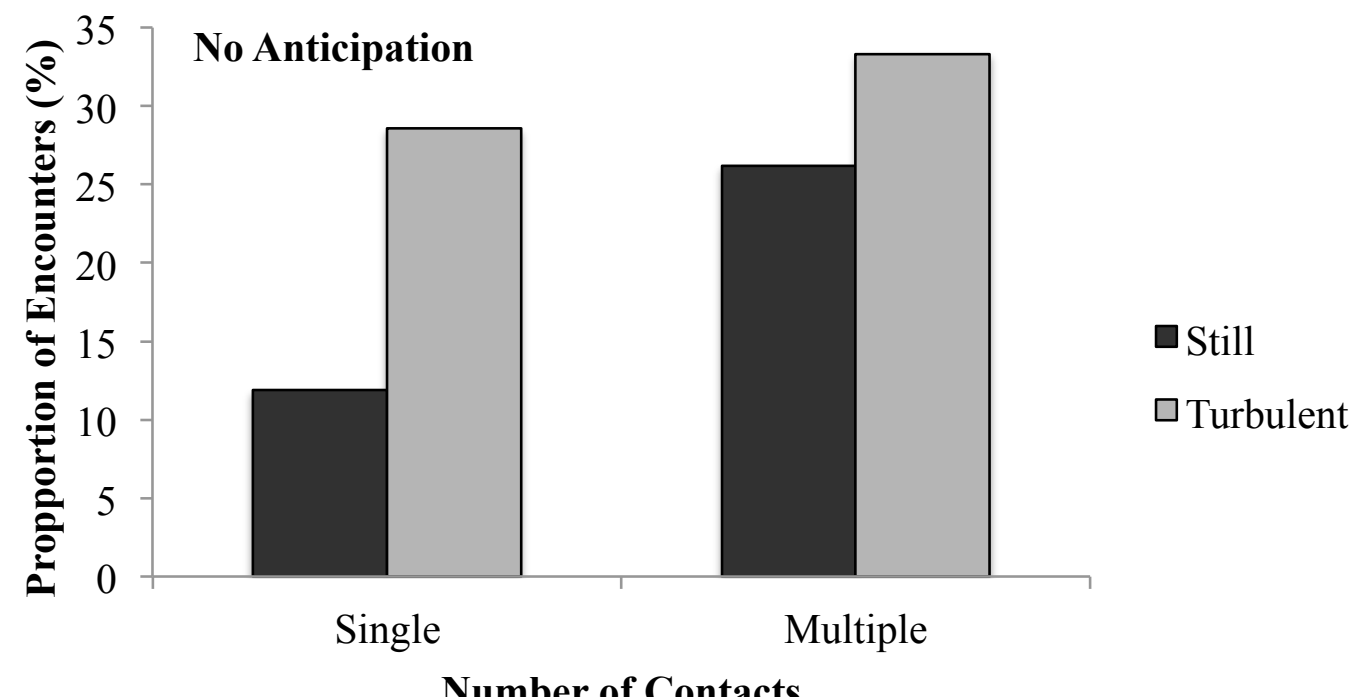

Figure 6 Encounters between copepods and Mnemiopsis leidyi individuals exhibiting no anticipatory behaviors with single or multiple contacts. Still $(n=16)$ and turbulent $(n=26)$ treatments were compared. 


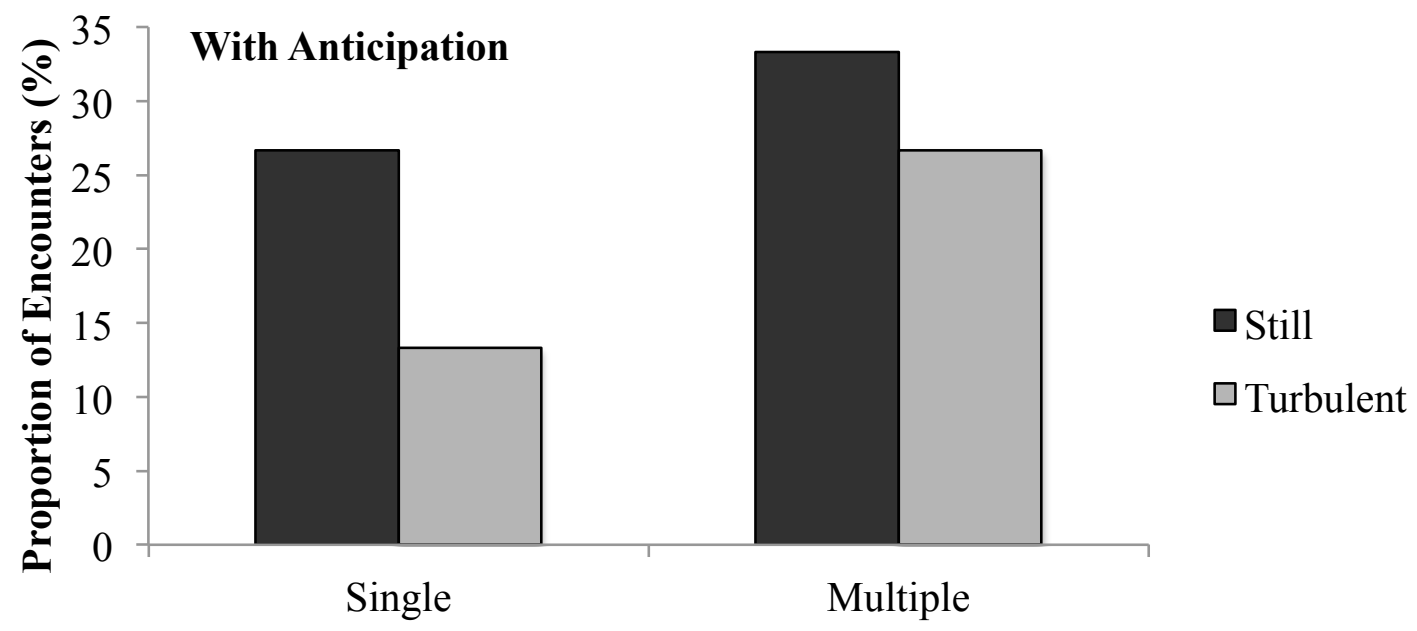

Number of Contacts

Fig. 7 Encounters between copepods and Mnemiopsis leidyi individuals exhibiting anticipatory behaviors with single or multiple contacts. Still $(n=9)$ and turbulent $(n=6)$ treatments were compared.

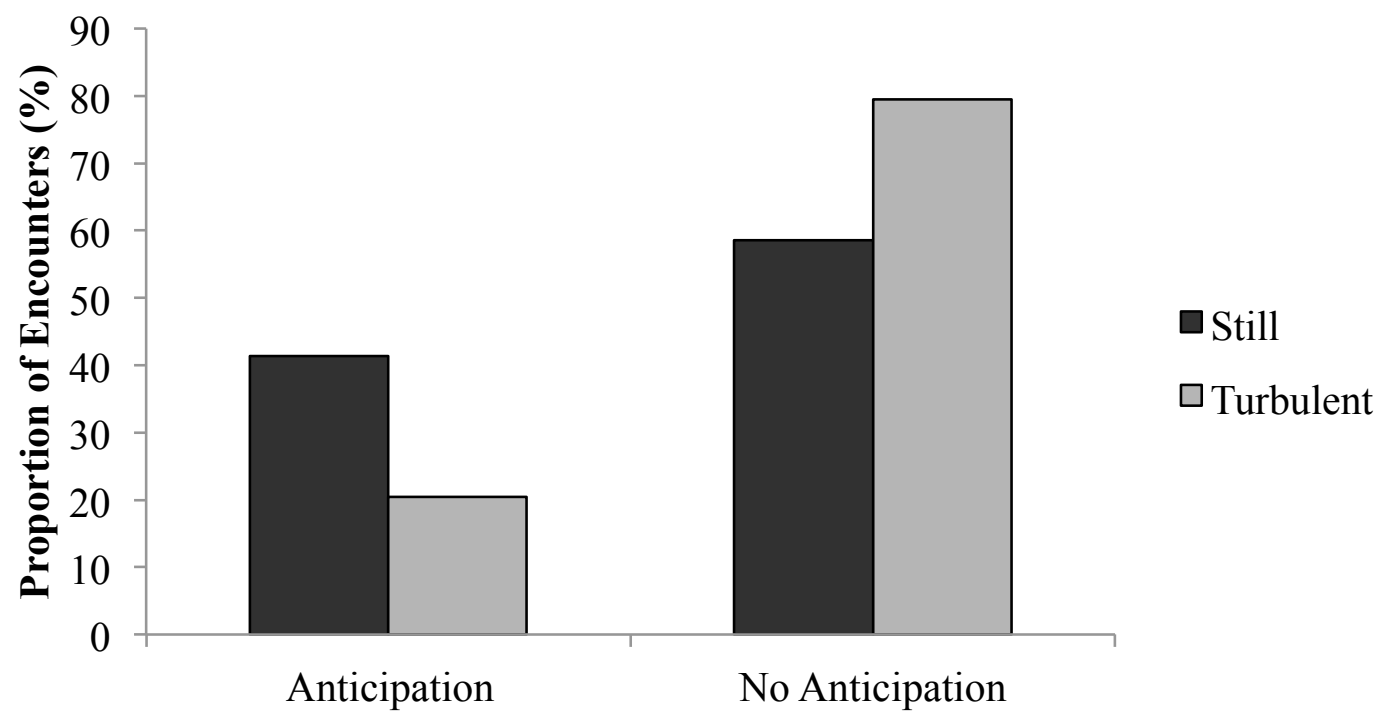

Fig. 8 Proportion of encounters between Mnemiopsis leidyi and copepods containing anticipatory behaviors in still $(n=29)$ and turbulent waters $(n=44)$. 




Fig. 9 Capture efficiency of the ctenophore Mnemiopsis leidyi when feeding on copepods in encounters containing anticipatory behaviors in still $(\mathrm{n}=29)$ and turbulent waters $(\mathrm{n}=44)$. 